\title{
MEDIACIÓN FAMILIAR INTERNACIONAL Y SUSTRACCIÓN DE MENORES
}

\author{
INTERNACIONAL FAMILY MEDIATION AND CHILD ABDUCTION
}

\author{
Celia Carrillo Lerma \\ Universidad de Murcia. España/Spain \\ ccarrillolerma@gmail.com
}

Recibido/Received: 02/02/2015

Aceptado/Accepted: 27/04/2015

\section{RESUMEN}

El presente trabajo versa sobre el estudio de la mediación como método amistoso de resolución de conflictos en materia de sustracción internacional de menores. Se analizan su regulación en Derecho europeo y en Derecho español y las ventajas de su puesta en práctica. El resultado obtenido es que la mediación puede ser una buena alternativa a la vía judicial para resolver estos asuntos, puesto que presenta mayores ventajas que inconvenientes, si bien no se trata de una práctica muy extendida.

\section{PALABRAS CLAVE}

Método amistoso, resolución de conflictos, Derecho europeo, Derecho español, ventajas.

\section{SUMARIO}

1. Introducción. 2. Importancia y ventajas de la mediación familiar internacional. 3. La mediación familiar a nivel europeo. 4. La mediación familiar a nivel nacional. 5. Especial referencia a la mediación en el contexto del Convenio de La Haya de 1980. 6. Resumen y conclusión. Bibliografía.

\begin{abstract}
The present paper deals with the study of the mediation as an amicable dispute settlement mechanism in the area of international child abduction. Its regulation in European law and Spanish law and the advantages of its implementation are analyzed. The result obtained is that mediation could be a good alternative to court proceedings in order to settle these issues since its advantages outweigh its disadvantages, while it is not a very common practice.
\end{abstract}

\section{KEYWORDS}

Amicable dispute settlement mechanism, European law, Spanish law, advantages.

\section{CONTENTS}

1. Introduction. 2. Importance and advantages of international family mediation. 3. Family mediation at European level. 4. Family mediation at national level. 5. Particular reference to mediation in the framework of the 1980 Hague Convention. 6. Summary and conclusion. References. 


\section{INTRODUCCIÓN}

La elevada cuantía de traslados o retenciones ilícitas de niños que en la práctica acaecen y el hecho de que la verdadera víctima de ellos sea un menor convierten el fenómeno conocido como sustracción internacional de menores en un tema de especial consideración.

Es palpable la preocupación desde diferentes sectores (los propios Estados, la Conferencia de La Haya, los distintos operadores jurídicos -jueces, abogados, autoridades centrales...- o la Unión Europea) e importantísima la labor que se realiza desde la Conferencia de La Haya a través de su Oficina Permanente y la Comisión Especial.

Resulta, asimismo, preocupante la falta de conocimientos e información que de las distintas posibilidades de actuación frente a estos problemas (procedimiento judicial, mecanismos amistosos de resolución de conflictos o medidas preventivas) tienen los operadores jurídicos y los propios particulares.

El panorama normativo es el que sigue:

- El Convenio de La Haya de 25 de octubre de 1980 (BOE núm. 202, de 24 de agosto de 1987; corr. de errores, BOE núm. 155, de 30 de junio de 1989, y BOE núm. 21, de 24 de enero de 1996) presenta deficiencias y ha quedado desfasado, por lo que no responde correctamente a la nueva realidad social. Deviene necesario elaborar un nuevo Convenio en el marco de la Conferencia, de mejor redacción y que dote de una protección más intensa al derecho de visitas y prevea una cooperación entre autoridades previa a la sustracción, que ayude a impedir su perpetración. Otro problema que plantea la aplicación del Convenio es que la mayor parte de los países de corte islámico no han ratificado o no se han adherido al Convenio.

- El Convenio europeo de Luxemburgo de 20 de mayo de 1980 (BOE. núm. 210, de 1 de septiembre de 1984) no presenta aplicabilidad alguna pese a continuar en vigor debido, entre otras cuestiones, a la entrada en vigor del Reglamento (CE) núm. 2201/2003 del Consejo, de 27 de noviembre de 2003, relativo a la competencia, el reconocimiento y la ejecución de las resoluciones judiciales en materia matrimonial y de responsabilidad parental (Reglamento Bruselas II bis) (D.O. núm. L 338, de 23 de diciembre de 2003).

- En el ámbito europeo, en la elaboración del Reglamento 2201/2003 no se optó, en materia de responsabilidad parental, por la mejor opción para su redacción, y la existencia del espacio europeo sin fronteras interiores requiere un refuerzo en la regulación de esta materia.

- En el ámbito interno se hace necesaria una reforma procesal que, entre otras cuestiones, regule un procedimiento a través del cual se cumpla con la protección y regulación de las visitas, que viene prevista convencionalmente pero que en la realidad carece de cauce específico, lo que provoca la aplicación analógica de los artículos 1901 a 1909 LEC 1881 por los órganos jurisdiccionales. Además, tanto el procedimiento de reconocimiento y exequatur como el de restitución se ubican en una norma decimonónica que ya debería estar derogada, si bien la pasividad del legislador ha representado una traba. Las Leyes de Jurisdicción Voluntaria y sobre Cooperación Jurídica Internacional en materia civil que tanto se hacen de rogar, sin duda influirán en el procedimiento de restitución.

La inadecuación parcial de los distintos instrumentos jurídicos en la materia (internacionales, transnacionales o estatales) para dar solución a este gran problema social, ya sea por las deficiencias que presentan, ya sea por los elementos sociológicos del asunto, ha dado lugar a la búsqueda de métodos alternativos de resolución de estos conflictos. 


\section{IMPORTANCIA Y VENTAJAS DE LA MEDIACIÓN FAMILIAR INTERNACIONAL}

Desde hace unos años se plantea si los problemas de vulneración de los derechos de guarda y custodia en supuestos de sustracción internacional de menores se resuelven del modo adecuado mediante la aplicación de los Convenios internacionales en la materia, especialmente del Convenio de la Haya de 1980 o, si por el contrario, estos han quedado desfasados a razón de la tipología de casos para los que están diseñados y no responden a la realidad actual.

Hoy día se comienza a poner en práctica nuevas formas de solución de este tipo de conflictos. Una de ellas es la mediación, que surge como alternativa a la vía jurisdiccional, y cuyas ventajas palpables son las que siguen:

- Origina menores costes, tanto al particular como al Estado.

- Constituye un medio más rápido, pues ofrece una solución a (más) corto plazo.

- $\quad$ Permite que los problemas familiares en los que aparece involucrado uno o varios menores permanezcan dentro del ámbito de la familia, sin inmiscuir a los medios de comunicación y a las autoridades, ya gubernamentales, ya judiciales, ni hacerlos públicos, que, en la mayoría de los casos, puede resultar traumático para el menor (uno de los objetivos de la mediación es aminorar los daños psicológicos del menor [Resolución del Parlamento Europeo de octubre 2011 sobre modalidades alternativas de solución de conflictos en el ámbito del Derecho civil, mercantil y de familia]). En otras palabras, garantiza la confidencialidad del asunto.

El acuerdo alcanzado se basa, exclusivamente, en la autonomía de la voluntad, por lo que es más posible que las partes queden satisfechas y cumplan voluntariamente.

Con un mediador bien formado en mediación familiar internacional y, a ser posible, con el asesoramiento de un abogado que conozca a fondo la materia, se ahorran las partes el riesgo de acudir a unas autoridades que, muy probablemente, desconozcan la correcta aplicación de los Convenios.

La mediación, que ahora también se abre al Derecho de familia (en tanto se trate de materias disponibles), surgió como una forma amistosa de dirimir conflictos en el ámbito civil y comercial. El Vademécum del Mediador del Parlamento Europeo para casos de sustracción de menores expone, de hecho, que conviene desarrollar y reforzar aún más la función del Mediador en este contexto.

La mediación puede ser un buen medio para aproximar a las partes e invitarlas a llegar a un acuerdo cuando el traslado o retención ilícita ya se ha producido pero, al contrario de los Convenios existentes en la materia, también puede lograr un acercamiento previo y evitar que la sustracción se perpetre.

Parece tratarse de un mecanismo más ventajoso que el recurso a los tribunales, si bien no existe garantía de que se alcance finalmente un acuerdo y, en principio, no impide que igualmente se reclame en juicio más tarde.

El éxito viene dado si se logra dar una solución al supuesto y todas las partes respetan el acuerdo de forma voluntaria. La esperanza de la resolución de conflictos por mediación radica en la confianza en ello, y es por lo que métodos como la mediación o la conciliación han sido llamados por algunos autores "métodos dulces de resolución de conflictos" (Glenn y Diago Diago).

Por supuesto, la mediación no puede suponer un retraso en la restitución del menor (Pérez Vera, 1981). 
Si bien la mediación puede resultar interesante en otros supuestos, existe una serie de casos donde lo es especialmente. Se trata de tres hipótesis en que se da un obstáculo a la restitución del menor al lugar de su residencia habitual: 1) el supuesto no se haya dentro del ámbito de aplicación de los Convenios o del Reglamento europeo; 2) el menor se halla en paradero desconocido; 3) algún motivo de denegación del retorno del menor resulta operativo (Caamiña Domínguez, 2011). Son casos en los que, por no poder darse otra solución, la mediación se presenta como la única opción viable.

En cualquier caso, la superioridad de la mediación frente a las vías contenciosas de resolución de conflictos radica en que, por regla general, unos progenitores inclinados a celebrar este tipo de acuerdo amistoso son unos progenitores prestos a su cumplimiento.

\section{LA MEDIACIÓN FAMILIAR A NIVEL EUROPEO}

En el marco del Consejo de Europa, el 21 de enero de 1998 se aprueba, por su Comité de Ministros, la Recomendación $\mathrm{N}^{0} \mathrm{R}$ (98)1 sobre la mediación familiar, que espolea a los Estados a instituir y promover la mediación familiar o reforzar la existente, así como a adoptar o consolidar las medidas necesarias para la puesta en funcionamiento de los principios que garanticen aquel resultado.

El 18 de enero de 2002 se adopta la Recomendación $N^{o}$ (2002) 10, que refuerza la mediación en materia civil, con principios complementarios para favorecer la mediación.

De otro lado, a raíz de la Directiva 2008/52/CE del Parlamento europeo y del Consejo, de 21 de mayo, en asuntos civiles en litigios transfronterizos (D.O.U.E. L136, de 24 de mayo de 2008, pp. 3-8.), se crea en el contexto de la Unión europea un programa de mediación transfronteriza y una red de mediadores familiares internacionales.

El proyecto emprendido consta de tres fases: la primera, de investigación; la segunda, de formación unificada en mediación familiar internacional; la última, una fase de divulgación (Criado Inchauspé, 2012).

El objetivo de la formación de estos mediadores consiste, de una parte, en informar a través de ellos al resto de operadores jurídicos (autoridades centrales, abogados, jueces...) de los Estados miembros de la UE sobre la mediación familiar internacional y, de otra, en continuar formando mediadores en cada Estado miembro. Estas son las dos formas de expandir la mediación familiar internacional (MFI).

Dicha fase se ha desarrollado a través de dos cursos, que han tenido lugar entre septiembre y octubre de 2011 y en febrero, marzo y abril de 2012.

El Cons. (16) de la Directiva 2008/52/CE establece la obligación a los Estados miembros de la UE de promover "la formación de mediadores y el establecimiento de mecanismos eficaces de control de calidad relativos a la prestación de servicios de mediación'. En el mismo sentido se revela el art. 4.2 de la Directiva.

En la fase de divulgación se procede a la creación de una red internacional de mediadores familiares por todos los Estados de la UE.

La persona que elige esta forma de resolución de conflictos ha de acudir a un mediador de su país que pertenezca a esta red internacional de mediadores.

La Directiva define “mediación”, en su artículo 3.a) como “un procedimiento estructurado, sea cual sea su nombre o denominación, en el que dos o más partes en un litigio intentan voluntariamente alcanzar por sí mismas un acuerdo sobre la resolución de su litigio con la ayuda de un mediador'.

Son supuestos en los cuales es posible acudir a la mediación los siguientes: 
a) El menor ha sido sustraído o retenido por el otro progenitor y se pretende hacerlo razonar para que lo devuelva voluntariamente o bien para que acceda a fijar un régimen de visitas a favor del progenitor no sustractor.

b) Existe riesgo de que el menor sea traslado o retenido ilícitamente por el otro progenitor, ya que éste conserva vínculos con otro Estado.

c) El otro progenitor desea trasladar su domicilio y el del menor al extranjero, y desea invitarlo a organizar el régimen de visitas por vía pacífica.

d) La persona que acude al mediador pretende mudarse al extranjero con el menor pero teme que el otro progenitor le denuncie por la sustracción del menor o menores.

La Directiva prevé que la mediación pueda ser idea de las partes, sugerencia o mandato de un juez o tribunal (art. 5), o prescripción legal por el ordenamiento jurídico de un Estado miembro [art. 3.a), pfo. $1^{\circ}$ in fine de la Directiva 2008/52/CE].

En cuanto a su ámbito material de aplicación, el Cons. (10) precisa que la Directiva se aplica a asuntos civiles y mercantiles que versen sobre materias disponibles por las partes. El Cons. (11), por su parte, recoge una lista de materias excluidas, así como el artículo 1.2. Asimismo, sólo se aplica a asuntos transfronterizos, concretados en el artículo 2.

El ámbito espacial de aplicación de la Directiva es el territorio de todos los Estados miembros de la UE a excepción de Dinamarca [Cons. (30) y art. 1.3].

El Cons. (13) lo califica de procedimiento voluntario que las partes pueden finalizar en cualquier momento. Ordena a los Estados a garantizar la posibilidad de que se puedan establecer límites temporales. El cómputo de inicio del procedimiento es, a falta de acuerdo escrito, "la fecha en que toman medidas concretas para iniciar el procedimiento de mediación".

Los Cons. (19-22) de la Directiva 2008/52/CE prevén la ejecución de estos acuerdos.

La razón de que se apueste por la fuerza ejecutiva de estos acuerdos radica en que "La mediación no debe considerarse como una alternativa peor que el proceso judicial por el hecho de que el cumplimiento del acuerdo resultante de la mediación dependa de la buena voluntad de las partes"' [Cons. (19) de la Directiva].

La mediación aparece también contemplada en otros instrumentos europeos con carácter especial para algunas materias como, por ejemplo, en el artículo 55.e) del Rgl. Bruselas II bis, que prevé el deber de las autoridades centrales de facilitar su celebración, en el ámbito concreto de la responsabilidad parental.

Desde el mes de julio de 2004 se encuentra disponible un Código de Conducta europeo de mediadores.

Es importante destacar la existencia del Mediador del Parlamento Europeo, una figura que existe desde 1987 y a la que puede acudir el ciudadano de forma gratuita. El Mediador asesora a las partes en la preparación del acuerdo y se asegura de que éste cumpla con la legalidad. Otras competencias del Mediador del PE son facilitar información sobre Ley aplicable y comunicar a las Autoridades competentes las irregularidades en la aplicación de los instrumentos jurídicos en la materia. Las notas que guían su función son las de independencia, imparcialidad y confidencialidad.

De acuerdo con los datos recogidos en el Vademécum del Mediador del PE, desde septiembre 2009 a diciembre 2011, la Oficina del Mediador ha registrado noventa y ocho solicitudes, de las cuales diez eran casos de mediación. En la mayor parte de asuntos el ciudadano denuncia una irregularidad en la aplicación o ejecución de los Convenios o del Reglamento Bruselas II bis. 
En cualquier caso, parece ser que hasta ahora se ha hecho escaso uso de la mediación en los Estados miembros de la UE, en particular, por temor a la preclusión de los breves plazos establecidos en el CH 1980 y a que el menor se adapte a su nuevo medio y pueda concurrir la causa de denegación del retorno del artículo 12.2 del Convenio (Estudio del Parlamento Europeo para la Comisión de Libertades Civiles, Justicia y Asuntos de Interior sobre sustracción parental transfronteriza de menores en la Unión Europea, 2015).

\section{LA MEDIACIÓN FAMILIAR A NIVEL NACIONAL}

Es de sobra conocido que, si bien las directivas europeas son igual de vinculantes que los reglamentos, mientras que éstos son directamente aplicables y ejecutables (self-executing), las directivas han de ser adaptadas al Derecho interno de cada Estado por los medios que éstos consideren pertinentes.

En relación a España, la Directiva 2008/52/CE se acondiciona en el ordenamiento jurídico español a través del RD-Ley 5/2012, de 5 de marzo, de mediación en asuntos civiles y mercantiles -DF 7a-, convalidado por Acuerdo de 29 de marzo de 2012.

Sin embargo, el mismo fue derogado por Ley 5/2012, de 6 de julio, de mediación en asuntos civiles y mercantiles (BOE. núm. 162, de 7 de julio de 2012) (Disposición Derogatoria única) y, como establece su Disposición Final $6^{\mathrm{a}}$, a través de ella se incorpora la Directiva al Derecho español.

Esta Ley se aplica no sólo a supuestos internacionales, sino también internos.

En su artículo 1 ofrece una definición de lo que por mediación entiende. Así, viene a ser “aquel medio de solución de controversias, cualquiera que sea su denominación, en que dos o más partes intentan voluntariamente alcanzar por sí mismas un acuerdo con la intervención de un mediador'. Guarda sintonía con el artículo 3 de la Directiva europea, que aporta una definición de los conceptos de mediación y mediador.

El mediador puede ser, o no, Licenciado en Derecho, pero ha de ser titulado universitario o de formación profesional superior, además de acreditar la realización de uno o varios cursos para ejercer como tal (art. 11.2 Ley 5/2012). También es posible que un asunto sea mediado por dos o más personas (art. 18 Ley 5/2012). Su función no es la de tomar una decisión por las partes ni la de obligarlas a cumplirla, sino la de mediar entre ellas, proponiendo soluciones al conflicto, para que las mismas partes alcancen un acuerdo regido únicamente por su libre voluntad.

El hecho de que el acuerdo sea voluntario hace bastante posible su cumplimiento de este mismo modo, lo que evitaría el largo y costoso proceso de reconocimiento y exequatur. No obstante, si esto llegara a ocurrir, el Cons. (20) de la Directiva, así como el Reglamento Bruselas II bis, admiten la fuerza ejecutiva de un acuerdo reconocido y declarado ejecutivo en otro Estado miembro. En relación con esto también se debe recordar que el artículo 955.1 LEC 1881 incluye, en el ámbito de aplicación del procedimiento de exequatur de resoluciones extranjeras en España, los acuerdos de mediación extranjeros, al regular la competencia de los juzgados de primera instancia para su resolución.

Debido a que se trata de un procedimiento voluntario y, en especial, a que el acuerdo alcanzado nace de la autonomía de la voluntad, nada impide que las partes acudan antes o después a los órganos jurisdiccionales. Podría decirse que tiene la misma naturaleza que un contrato, pero que puede llegar a gozar de fuerza ejecutiva, como una resolución judicial o un laudo arbitral. 
En relación a esta cuestión, el Cons. (24) de la Directiva establece el mandato para los Estados miembros de garantizar a los particulares que los plazos de caducidad y prescripción no constituirán un obstáculo al ulterior deseo de las partes de acudir a los órganos jurisdiccionales (para España, vid. art. 4 Ley 5/2012).

Recientemente, el Vademécum del Mediador del PE ha definido el acuerdo de mediación como "un contrato privado entre las partes" y ha afirmado que el consentimiento es el "elemento de legitimidad jurídica del contrato".

En cuanto al ámbito de aplicación de la Ley, será:

a) Material. Se aplica a mediaciones en asuntos civiles o mercantiles, ya sean o no trasfronterizos (art. 2.1 Ley 5/2012; se debe recordar que la Directiva se refiere únicamente a asuntos transfronterizos, si bien no impide a los Estados aplicar sus disposiciones a la mediación interna. El sistema español es un sistema monista [Calvo Caravaca; Carrascosa González, 2013]). Lo han de ser conforme al Derecho español, y han de referirse a derechos disponibles por las partes en virtud de la Ley que hubiera resultado aplicable a los mismos de haberse entablado un proceso judicial. El artículo 2.2 excluye expresamente la mediación penal, con las AA.PP., laboral y en materia de consumo.

b) Espacial. Ha de existir un punto de conexión con España: sumisión expresa o tácita de las partes o, en su defecto, que al menos una de ellas tenga su domicilio en España y la mediación se realice en territorio español (art. 2.1.II).

En cuanto al procedimiento de mediación, viene contenido en la misma Ley 5/2012 (arts. 19-22). No resulta necesaria la previsión de una ley aplicable al asunto porque el mismo no se rige por una ley sino por la voluntad de las partes, con el límite de la disponibilidad de los derechos en cuestión y el de que el acuerdo alcanzado no sea contrario al Derecho que señalen las normas de conflicto aplicables a la institución de que se trate (Calvo Caravaca y Carrascosa González, 2013).

El procedimiento termina con el acta final, firmada por las partes y el mediador, que viene a constituir un contrato.

Los derechos no disponibles en asuntos civiles y mercantiles suelen ser en materia de familia y laboral -y así lo recoge el Cons. (10) de la Directiva 2008/52/CE-, que como se conoce, su naturaleza de Derecho privado ha sido profundamente discutida. Habrá siempre aspectos que sean disponibles y otros que no lo sean.

Finalmente, a la ejecución de un acuerdo de mediación, se refieren los artículos 25 a 27 de la Ley.

El artículo 27.3 de la Ley, en sintonía con el Cons. (19) de la Directiva -y en cumplimiento del art. 12.3 CC-, veta la posibilidad de ejecución del acuerdo extranjero de mediación que "resulte manifiestamente contrario al orden público español".

Aparte de lo anterior, el acuerdo no se ejecutará en España si no se ha declarado su fuerza ejecutiva por la autoridad extranjera competente, a menos que se eleve, a petición de las partes o de una con el consentimiento de las otras, a escritura pública por un notario español (art. 27.1 y 2 Ley 5/2012).

$\mathrm{Si}$, por el contrario, ha de ejecutarse en otro país, la Ley establece que se deberá de elevar a escritura pública el acuerdo y cumplir los requisitos exigidos, en su caso, por los convenios en que España sea parte y las normas de la UE (art. 25.3 Ley 5/2012). Pero "Esta previsión carece de todo sentido, puesto que la ejecución en otro país de una escritura pública española la regulará el DIPr. De ese otro Estado. Por ello, lo que indica este art. 25.3 Ley 5/2012 no obliga a las autoridades extranjeras competentes, para las que dicho precepto resulta totalmente irrelevante"' (Calvo Caravaca y Carrascosa González, 2013). 
Se puede pedir la homologación por el tribunal que estaba conociendo del asunto antes de someterlo a mediación (art. 25.4 Ley 5/2012). La competencia para la ejecución en estos casos será de este tribunal (art. 26.1). En los demás casos, será del Juzgado de Primera Instancia del lugar de firma del acuerdo de mediación (art. 26.2).

Por último, se debe mencionar también que la Ley $5 / 2012$, en su DF $3^{\text {a }}$, apartado quince, por la que modifica algunos artículos de la Ley $1 / 2000$, de enjuiciamiento civil, altera la redacción del art. 517.2.2 de esta Ley, incluyendo los acuerdos de mediación elevados a escritura pública como título ejecutivo.

\section{ESPECIAL REFERENCIA A LA MEDIACIÓN EN EL CONTEXTO DEL CONVENIO DE LA HAYA DE 1980}

La mediación requiere de un doble grado de cooperación: entre Estados y entre los progenitores del menor (Monéger, 2004).

Así, el artículo 7, párr. 2º letra c) $\mathrm{CH} 1980$ recoge, entre las medidas que deben adoptar las Autoridades centrales, la de asegurar el retorno voluntario del menor o ayudar a las partes a alcanzar un arreglo amistoso. En sintonía, el artículo 10 establece la obligación de la Autoridad central de proceder a la adopción de medidas para lograr la restitución voluntaria del menor una vez efectuada la solicitud de retorno y comprobado que el menor se halla en el territorio del Estado requerido.

La Comisión Especial de la Conferencia, en sus Conclusiones y Recomendaciones de 1 a 10 de junio de 2011 informa, a propósito de la mediación, sobre "los numerosos desarrollos en el uso de la mediación en el marco del Convenio de 1980" (apdo. 57). Por otra parte, también “celebra al Proyecto de Guía de Buenas Prácticas de Mediación en virtud del Convenio de 1980" y encarga a la Oficina Permanente las revisiones a la Guía (apdo. 58).

Es momento de referirse a la mencionada Guía, de gran importancia en el contexto del Convenio de La Haya de 25 de octubre de 1980. Como establece en su apartado 49, "El Convenio de La Haya de 1980 sobre Sustracción de Menores promueve la búsqueda de soluciones amigables", con referencia a sus artículos 7 y 10, ya citados.

En su apartado 30, la Guía contempla algunas situaciones de hecho en que puede resultar útil el recurso a la mediación en el marco del Convenio. Así, puede ayudar a que se acceda a la restitución voluntaria del menor o a que se dicte una orden de restitución con base en el consentimiento de las partes; a que se acepte la reubicación del niño siempre que se proteja el derecho de visita del perjudicado; a facilitar el contacto entre el niño y el progenitor no sustractor mientras dure el proceso; a facilitar la restitución rápida y segura del menor o, incluso, a evitar que la sustracción llegue a perpetrarse.

Destaca la conveniencia de iniciar el proceso de restitución en virtud del Convenio antes de acudir a la mediación, y la posibilidad de suspenderlo mientras dure la mediación. Enumera una serie de ventajas significativas en las letras a) a h) aunque, tal vez, la más importante sea la contenida en esta última: "Por último, el tribunal puede dar seguimiento al resultado de la mediación y garantizar que el acuerdo tendrá efecto jurídico en el sistema jurídico al cual se sustrajo al niño, al convertir el acuerdo en una orden del tribunal o adoptando otras medidas. El tribunal podrá, asimismo, asistir en garantizar que el acuerdo tenga efecto jurídico en las demás jurisdicciones pertinentes"' (apdo. 61).

El apartado 65 alienta la cooperación entre mediadores y organismos que ofrecen la mediación y las Autoridades Centrales y judiciales. 
Recuerda la importancia de tener en cuenta la complejidad que presentan los casos de mediación internacional y la necesidad de que se tengan en cuenta, entre otras cuestiones, la posibilidad de que las partes sean de cultura y religión diferentes o tengan dificultades idiomáticas, o que se facilite el suministro de los documentos de viaje necesarios.

Asimismo, considera necesaria la formación específica en materia de sustracción internacional de menores a los mediadores familiares internacionales a los que se encargue este tipo de asuntos (apdo. 98), así como su formación continua para que sigan siendo aptos (apdo. 104).

La Guía recomienda dejar la puerta abierta a la mediación y demás mecanismos amistosos de resolución de conflictos en cualquier momento del proceso: previamente, durante el curso del mismo e incluso en la fase de ejecución (apdo. 121).

También cabe la mediación indirecta y a larga distancia cuando no sea posible o adecuada la presencia de todas las partes en la sesión (apdo. 172).

Como es natural, debido al carácter urgente del procedimiento de restitución en el marco del Convenio, la mediación debe cumplir con plazos muy estrictos, por lo que debe limitarse su alcance (apdo. 183), mediante un equilibrio “entre la inclusión de las cuestiones que sean necesarias para llegar a un acuerdo amistoso" y el cumplimiento de los plazos (apdo. 189).

El apartado 204 contempla como principios informadores de la mediación los de neutralidad, independencia, imparcialidad y justicia.

Asimismo, como es natural, debe tenerse en cuenta el interés superior del menor y su bienestar (apdo. 212), así como su participación (informarle y ser escuchado). Esto último se hará, como siempre, en consideración a su edad y grado de madurez (apdo. 239, entre otros).

Para los casos en que los menores inmiscuidos tengan un alto grado de conflicto, la Guía recomienda, cuando sea posible, la co-mediación (actuación de dos mediadores) (apdo. 223 en concreto, y 98, entre otros, en general).

También se prevé la posibilidad de que participen terceros en las sesiones de mediación, siempre que su presencia pudiera ser de ayuda (apdos. 253 a 255).

Establece el apartado 275 que "Debería considerarse cuidadosamente el uso de la mediación en los casos donde existe un tema de violencia doméstica. Es necesaria la formación suficiente para evaluar la aptitud de un caso para la mediación'. En este sentido, no puede poner en riesgo la vida o seguridad de ninguna de las personas implicadas en la mediación (apdo. 277).

En cuanto a la ejecución de los acuerdos de mediación, la Guía considera que la cooperación entre autoridades "puede ser necesaria para ayudar a facilitar la ejecutoriedad del acuerdo en todos los Estados pertinentes" (apdo. 302). En cuanto a los Estados, deberían considerar la promulgación de normas que faciliten los procedimientos de declaración de ejecutoriedad de estos acuerdos (apdo. 304).

Además, para evitar que el traslado o la retención ilícita se produzca, deberían promoverse los acuerdos voluntarios y facilitar la mediación en cuestiones de custodia o visitas (apdo. 318).

De acuerdo con el apartado 60, "En algunos Estados, los programas de mediación desarrollados específicamente para los casos de sustracción internacional de niños ya están prestando esos servicios de manera exitosa'".

En el caso concreto de España, no parece que esté muy extendida la mediación, ni en el ámbito familiar ni en ningún otro. No obstante, se espera que en un futuro se vaya expandiendo poco a poco, mediante la formación de los profesionales que sean necesarios y la información a los particulares y operadores jurídicos. 
Pero la mediación no es el único mecanismo posible para evitar una sustracción o solucionar estos conflictos cuando ya han nacido, y así aboga por ellos la Guía de Buenas Prácticas en su apartado 324, ofreciendo una mención a varias de ellas, la más conocida, la conciliación.

\section{RESUMEN Y CONCLUSIONES}

Primera. Resulta notoria la gravedad del tema tratado, de una parte, por la gran cuantía de traslados o retenciones ilícitos de niños que en la práctica acaecen y, de otra, debido a quién es la verdadera víctima de los mismos: el menor.

Segunda. Se ha podido constatar la inadecuación parcial de los distintos instrumentos jurídicos en la materia (internacionales, transnacionales o estatales) para dar solución a este gran problema social, ya sea por las deficiencias que presentan, ya sea por los elementos sociológicos del asunto.

Existe, no obstante, una preocupación desde diferentes sectores por ofrecer la mejor solución a este tipo de conflictos familiares.

Tercera. Resulta preocupante la falta de conocimientos e información que de las distintas posibilidades de actuación frente a estos problemas (procedimiento judicial, mecanismos amistosos de resolución de conflictos o medidas preventivas) tienen los operadores jurídicos y los propios particulares.

Cuarta. Existen varias soluciones a la mano de los Estados, del legislador o de los mismísimos interesados, como dar nueva redacción al Convenio de La Haya de 1980, mas, mientras ello no ocurre resultan muy interesantes los medios amistosos de resolución de conflictos, como la mediación, que de llegar a buen puerto pueden proporcionar una solución a estos asuntos en la que queden satisfechas todas las partes implicadas, en mayor o menor medida, y que ocasione menos perjuicios al menor.

Quinta. Las ventajas más destacables del recurso a la mediación son que origina menores costes, constituye un medio más rápido con solución a corto plazo, garantiza la confidencialidad del asunto, aumenta las probabilidades de cumplimiento voluntario, hace posible el asesoramiento de profesionales que conocen a fondo la materia, puede ayudar a evitar la sustracción y es operativa en supuestos en que no cabe otra solución más que la amistosa.

Sexta. Entre los inconvenientes se encuentra que el recurso a la mediación se utilice para demorar el procedimiento judicial y que transcurran los breves plazos establecidos en los instrumentos jurídicos aplicables en la materia, por lo que se hace necesario el establecimiento de garantías para que ello no ocurra.

Séptima. Tanto el Consejo de Europa, como la Unión Europea y el Estado español se han pronunciado sobre la mediación en materia de sustracción internacional de menores. Su uso se ha implementado legislativamente en Europa. No obstante, parece que en la práctica no se ha hecho gran uso de la mediación.

En definitiva, resulta evidente que el uso de la mediación como método de resolución de conflictos encierra mayores virtudes que desventajas. No obstante, no se trata de una práctica muy extendida, si bien cabe esperar que a largo plazo aumente su empleo, lo que supondría, previsiblemente, un final (algo) más feliz que el derivado de un proceso judicial. 


\section{BIBLIOGRAFÍA}

CAAMIÑA DOMÍNGUEZ, C. M. (2011). "La mediación ante el secuestro internacional de menores". Revista Internacional de Estudios de Derecho Procesal y Arbitraje, 1: 1-35.

CALVO CARAVACA, A. L. y CARRASCOSA GONZÁLEZ, J. (2013). "Protección de menores". En A. L. Calvo Caravaca y J. Carrascosa González. Derecho internacional privado, vol. II. Granada: Comares, pp. 387-477.

CALVO CARAVACA, A. L.; CARRASCOSA GONZÁLEZ, J. y CAAMIÑA DOMÍNGUEZ, C. M. (2011). "Tutela y protección de menores en el derecho internacional privado" en M. Yzquierdo Tolsada y M. Cuena Casas (dirs.) Tratado de Derecho de la Familia. Vol. VI. Pamplona: Aranzadi, pp. 505-658.

CRIADO INCHAUSPÉ, A. (2012). "Bruselas impulsa un ambicioso proyecto de crear una red de mediadores familiares internacionales en conflictos de sustracción internacional de menores". Diario jurídico. En: http://www.diariojuridico.com/actualidad/noticias/bruselas-impulsa-un-ambicioso-proyect o-de-crear-una-red-de-mediadores-familiares-internacionales-en-conflictos-de-sustraccion-de-menores. html (consultado 25/07/2013).

DE LA ROSA CORTINA, J. M. (2010). Sustracción parental de menores. Aspectos civiles, penales, procesales e internacionales. Valencia: Tirant Lo Blanch.

DIAGO DIAGO, M. P. (2008). "Aproximación a la mediación familiar desde el Derecho internacional privado", En A. L. Calvo Caravaca y E. Castellanos Ruiz (coords.) La Unión Europea ante el derecho de la globalización. Madrid: Colex, pp. 265-298.

FULCHIRON, H. (2004). Les enlévements d'enfants à travers les frontières. Brussels: Bruylant.

GALLANT, E. (2004). Responsabilité parentale et protection des enfants en Droit International Privé. Vol. 9. Paris: Defrénois.

GÓMEZ BENGOECHEA, B. (2002). Aspectos civiles de la sustracción internacional de menores. Problemas de aplicación del Convenio de la Haya de 25 de octubre de 1980. Madrid: Dykinson.

HERRANZ BALLESTEROS, M. (2004). El interés del menor en los Convenios de la Conferencia de La Haya de Derecho Internacional Privado. Valladolid: Lex Nova.

HONORATI, C. (2013). "Sottrazione internazionale dei minori e diritti fondamentali", RDIPP, 49-1, 2013: 5-42.

LOPES PEGNA, O. (2013). “'L'interesse superiore del minore nel regolamento n.2201/2003”, RDIPP, 49-2, 2013: 357-384.

LOWE, N.; EVERALL, M. y NICHOLLS, M. (2005). The new Brussels II Regulation. A supplement to international movement of children. Bristol: Family Law.

PÉREZ VERA, E. (1981). "Informe explicativo del Convenio de 1980 sobre sustracción de menores", Tiré à part des Actes et documents de la Quatorzième session (1980), Tome III. Conferencia de La Haya de Derecho internacional privado, 1982: 1-44. 


\section{Breve currículo:}

\section{Celia Carrillo Lerma}

Licenciada en Derecho por la Universidad de Murcia en 2011. Máster en investigación en Derecho en la UMU en 2013. Programa de Doctorado en Derecho en la UMU desde 2013 en la línea de investigación "Tratamiento del elemento de extranjería", dirigida por el Dr. Javier Carrascosa González. Colaboradora del Área de Derecho Internacional Privado de la Facultad de Derecho de la UMU y abogada desde 2011. Autora de diversas publicaciones en revistas y capítulos de libro. 